\title{
COMMENT \\ Policy priorities for child health: results from a membership survey of the Society for Pediatric Research
}

\author{
Shetal Shah ${ }^{1}$, Vivek Balasubramaniam ${ }^{2}$, Heather L Brumberg ${ }^{1}$ and Lee Sanders ${ }^{3}$ \\ Pediatric Research (2018) 84:6-9; https://doi.org/10.1038/s41390-018-0034-8
}

Within the child-health advocacy community, pediatric researchers occupy a unique niche. Compared with pediatric colleagues who do not self-identify as researchers, pediatric investigators are more likely to have affiliations with academic medical centers, to be subspecialty-care providers, and to benefit from federal funding. ${ }^{1}$ Pediatric researchers also often have dual roles as both clinician and researcher, which may influence their perceptions of child-health policy priorities. Though the pediatric research organizations have historically identified advocacy as an essential part of their mission, the legislative priorities of their membership have not been clearly described. Understanding these priorities is integral to advancing both pediatric science and healthcare.

Currently, academic pediatric advocacy is led by the Pediatric Policy Council, a national, cross-institutional body including representation from the American Academy of Pediatrics (AAP), as well as organizations representing academic pediatricians, department chairs, and pediatric researchers. The group develops consensus policy statements, congressional letters, and other memoranda representing the generalized academic pediatric community's perspective. Another key pediatric organization driving pediatric advocacy is the AAP. The AAP, representing $\sim 66,000$ pediatricians of all practice types, releases the annual "Agenda for Children", which outlines policy principles relevant to child health, and recently recommended specific congressional and administrative actions in its "Blueprint for Children". 2 While pediatric researchers may share some or all of the aims outlined in these AAP documents, the advocacy issues of greatest concern to pediatric scientists have not been well studied.

To gain insight into the legislative priorities for this administration and provide an advocacy template for the remainder of the 45th United States Presidential Administration, the Society for Pediatric Research (SPR) initiated a member survey in the fall of 2016. Membership in SPR requires an advanced degree and publication of several peer-reviewed publications. Applicants must be nominated by a current member and be less than 55-years-old . ${ }^{3}$

The survey tool, created by SPR's Advocacy Committee, listed five major advocacy priorities thought to be of significant concern to clinicians. A separate list was created for issues of importance to pediatric researchers (Table 1). The survey also included demographic information including participant sex, geographic location, clinical practice characteristics, terminal degree(s), academic rank, years since post-graduate training, and extramural funding status. The survey was sent four times to all active SPR members. Each participant was asked to rank their priorities $(1=$ most Important, 5= least Important)—on each of the provided lists, ranking priorities first, "as a pediatrician" and, separately, "as a researcher". A free-text option was provided for respondents to write-in an issue not addressed.

Point values were inversely assessed for each rank, where an issue received 5 points if ranked first by a respondent, 4 points if ranked second. This continued for each priority, with the fifth issue ranked by a respondent receiving 1 point. Averages for each issue were calculated as a mean rank score. The percentage of respondents who ranked each priority as being "Most Important" was also analyzed.

Of 2785 survey links distributed, 44 were returned as invalid email addresses. Of the remaining 2741 invitations, 1482 (54.1\%) emails were opened and 571 (20.8\%) completed the online survey.

The respondent characteristics mirrored the overall SPR population. Respondents were predominantly male (59\%). Nearly one in four (24.6\%) were $26-35$ years post-training and $17.2 \%$ were more than 35 years post-training. Majority were at an academic rank of Professor (54.6\%) or Associate Professor (29.3\%). Medical Doctorate was the most common (64.3\%) sole-terminal degree. Nearly half of the respondents practiced in the Midwest or the South, and $77.1 \%$ practiced sub-specialist pediatrics, $7.2 \%$ practiced general pediatrics, and $11 \%$ reported no clinical activity. Most $(87.6 \%)$ practiced in urban settings. Over $80 \%$ were based at an academic medical center, with over $50 \%$ of the total survey group working primarily in the inpatient setting. In addition to SPR membership, 488 of 551 respondents (88.6\%) self-identified as associated with other pediatric organizations. Nineteen percent work full time in clinical practice, $13 \%$ work full time in clinical research, $9.7 \%$ work full time in basic research, and $15.7 \%$ work across clinical practice, clinical research and administration. Most (77.6\%) receive extramural funding for research.

\section{PRIORITIES AS A RESEARCHER}

When asked to rank the priorities from "a researcher's perspective," increasing funding for the National Institutes of Health received $69.4 \%$ of first-place votes, and was the issue with the highest rank score. The second-highest priority by rank score was increasing efforts to allow federal funding of issues related to gun violence and research, which $16.6 \%$ of surveyed members rated as their top priority. Providing input on policies impacting child poverty was ranked third, advising the Office of Human Research Protection on their "Common Rule," which seeks to create a single, federal Institutional Review Board to facilitate multi-center studies, and supporting epigenetic evaluation of environmental toxins

\footnotetext{
${ }^{1}$ New York Medical College, Valhalla, NY, USA; ${ }^{2}$ University of Wisconsin, Madison, WI, USA and ${ }^{3}$ Stanford University, Palo Alto, CA, USA
} Correspondence: Shetal Shah (shahs2@wcmc.com)

Received: 20 March 2018 Accepted: 1 April 2018

Published online: 18 June 2018 
Policy priorities for child health: results from a membership...

$S$ Shah et al.

Table 1. Listed advocacy priorities chosen for inclusion

Priorities as a pediatric researcher

Priorities as a pediatric clinician

Increasing Funding for the National Institutes of Health

(NIH funding was increased by $\$ 1.7$ Billion dollars 2015 in response to a concerted advocacy effort by the biomedical research community. However, the NICHD funding payline remains at $9 \%$ from a historical average of $15-20 \%$.)

Gun Violence Research Ban

(As part of federal law enacted in the 1980s, the Centers for Disease Control and National Injury Prevention Centers are forbidden from analyzing deaths and injuries which occur from gun violence. The government can also not explicitly use federal research dollars to investigate gun-related issues.)

\section{Input on the OHRP Common Rule}

(In attempt to streamline the process of institutional approval for multicenter studies, the federal government issued draft regulations for a national Institutional Review Board which, if successfully navigated, would prevent the need for IRB approval at each participating site.)

Providing Scientific/Policy Input on Social Programs which Affect Children in Poverty

(Child poverty is epidemic and a potential social determinant of health. Poverty imparts lasting sequella to kids, particularly children under 3 years of age. Many social programs which affect poverty rates are under legislative threat; these include nutrition programs, Medicaid Expansion, SNAP funding "Food Stamps," and early education funding.)

Supporting the impact and neurodevelopmental evaluation of environmental toxicants on health across generations, including funding programs for lead prevention and it's epigenetic impacts

(Many of the chemicals to which children are routinely exposed are untested for neurodevelopmental effects. SPR can join with other organizations in strengthening mechanisms for approval of chemicals to which children will be exposed through research, including requesting safety thresholds be established for many chemicals and requesting information on fetal consequences of exposure.)

\section{Medicaid Parity Payment}

(As part of the Affordable Care Act, Medicaid payment was increased for many primary care providers to be on par with Medicare payment rates. As traditionally, Medicaid paid $\sim 80 \%$ of Medicare rates, this financial increase was welcomed by many pediatric providers in the Medicaid program and, by some measures, led to increased healthcare access. The payment increased expired several years ago. While some states have maintained the increase via state government appropriations, no federal extension of these payments have occurred.)

Malpractice Reform

(The Affordable Care Act included pilot programs for Malpractice reforms based on policy evidence from multiple sources. However, federal tort reform has lacked urgency and sustainability.)

Increasing Child Health Care Access

(Federal programs are based on eligibility, however often it is proposed that programs and/or states receive "BLOCK GRANTS" which limit the amount of funding the program receives for eligible children and their families.)

Preventing Pediatric Drug Shortages

(Periodic shortages in the supply of pharmaceuticals disproportionately affect pediatric and neonatal medicines since they are more likely compounded. Proposals aimed at reducing these shortages have been proposed.)

Preserving Antibiotic Use/Preventing Emergence of Antibiotic Resistance (with the concern that antibiotics resistance is rapidly emerging, federal funds could be appropriated to increase antimicrobial stewardship programs across hospitals and to reduce the burden of antibiotic use in agriculture as part of a larger plan to reduce the emergence of resistant pathogens)

Table 2. Advocacy priorities from the standpoint of a pediatric researcher

\begin{tabular}{|c|c|c|c|c|c|c|c|}
\hline \multirow[t]{2}{*}{ Issue } & \multirow[t]{2}{*}{ Reponses } & \multicolumn{5}{|c|}{$\begin{array}{l}\text { Number of times (percent) issue ranked as } 1 \text { (most important) to } 5 \\
\text { (least important) }\end{array}$} & \multirow[t]{2}{*}{$\begin{array}{l}\text { Mean rank } \\
\text { score }\end{array}$} \\
\hline & & 1 & 2 & 3 & 4 & 5 & \\
\hline Addressing the Gun Violence Research Ban & 541 & $90(16.6 \%)$ & $160(29.6 \%)$ & $98(18.1 \%)$ & $84(15.5 \%)$ & $109(20.2 \%)$ & 3.07 \\
\hline $\begin{array}{l}\text { Providing input on programs which affect child } \\
\text { poverty }\end{array}$ & 542 & $56(10.3 \%)$ & $131(24.2 \%)$ & $168(31.0 \%)$ & $130(24.0 \%)$ & $57(10.5 \%)$ & 3.00 \\
\hline $\begin{array}{l}\text { Supporting epigenetic evaluation of environmental } \\
\text { toxins, including lead prevention }\end{array}$ & 548 & $8(1.5 \%)$ & $52(9.5 \%)$ & $129(23.5 \%)$ & 175 (31.9\%) & $184(33.6 \%)$ & 2.13 \\
\hline
\end{tabular}

were ranked fourth and fifth respectively. Mean scores and ranks are shown in Table 2.

\section{PRIORITIES AS A PEDIATRICIAN}

When asked to rank priorities from "a clinician's perspective," 229 of 545 (43.6\%) participants ranked "Increasing Healthcare Access" as their primary issue, yielding a mean rank score of 3.90 (Table 3). Reinstitution of Medicaid payment parity at the federal level (which would pay primary care pediatricians rates equivalent to Medicare) was second, receiving 135 (26.2\%) first-place ranks.
Preventing pediatric drug shortages, preserving antibiotic use, and malpractice reform were lower priorities.

Survey responses suggest SPR members envision dual, interrelated priorities for child-health advocacy-particularly, efforts to protect all children by supporting both the stability of Medicaid program and increased NIH funding. While the Medicaid program is well known as a primary insurer for children in low-income communities, it less often is recognized as the leading source of funding for most children hospitals and subspecialty-care centers, on which pediatric researchers depend. And while the $\mathrm{NIH}$ is well known as an international beacon of peer-reviewed excellence in 
Table 3. Advocacy priorities from the standpoint of a pediatrician

\begin{tabular}{|c|c|c|c|c|c|c|c|}
\hline \multirow[t]{2}{*}{ Issue } & \multirow[t]{2}{*}{ Reponses } & \multicolumn{5}{|c|}{$\begin{array}{l}\text { Number of times (percent) issue ranked as } 1 \text { (most important) to } 5 \text { (least } \\
\text { important) }\end{array}$} & \multirow[t]{2}{*}{ Mean rank score } \\
\hline & & 1 & 2 & 3 & 4 & 5 & \\
\hline Medicaid payment parity & 515 & $135(26.2 \%)$ & $146(28.4 \%)$ & $87(16.9 \%)$ & $106(20.6 \%)$ & $41(8.0 \%)$ & 3.44 \\
\hline Preventing pediatric drug shortages & 524 & $73(13.9 \%)$ & $120(22.9 \%)$ & $131(25.0 \%)$ & $135(25.8 \%)$ & $65(12.4 \%)$ & 3.00 \\
\hline
\end{tabular}

discovery science, it is less often recognized as a the leading source of funding for supporting the training and early-career trajectories of pediatric subspecialists, which determine the health of all children, particularly those with chronic illness.

Child-health organizations should consider these dual priorities. The AAP, for example, has consistently supported advocacy efforts to prevent major changes in the structure and funding for Medicaid and the Children's Health Insurance Program, ${ }^{2,4}$ with a less consistent focus on needs to support research and subspecialty-training funding. By contrast, biomedical research advocacy organizations such as the Federation of Societies for Experimental Biology (of which SPR is a member organization) remain focused on $\mathrm{NIH}$ funding appropriations and efforts to strengthen the pipeline of the research workforce. 5

Respondent's stated that priorities may also reflect their ongoing, longitudinal experience with an austere research funding environment, particularly at the federal level. Though the $\mathrm{NIH}$ budget (in constant dollars) increased by $50 \%$ in the past 20 years, the majority of that increase was seen in the late $1990 \mathrm{~s}^{5-7}$ Since 2003 , the total NIH budget decreased by $19.3 \%$. Factoring in budget cuts, inflationary loses and sequestration, NIH has lost an estimated $22 \%$ of its purchasing power. ${ }^{8}$ The number of R01 grants and equivalent awards also decreased by $\sim 20 \%$, and the success rates were reduced by $33.8 \%{ }^{8,9}$ In Fiscal Year (FY) 2016, the National Institute of Child Health and Disease success rate was $13.2 \%$, among the lowest of the institutes. ${ }^{10,11}$ The average age of the funded scientific investigators has increased. Graduating pediatric-subspecialty trainees are avoiding research careers. $^{12}$ The recent $\$ 2$ billion increase in $\mathrm{NIH}$ funding, as applied to the FY 2017 Omnibus Bill, was maintained only through September 2017, and the recent proposal to increase funding by another $\$ 1.1$ billion represents a one-time down payment in reversing these trends. In fact, the President's most recent budget proposed an NIH budget of $\$ 26.9$ billion, a $26.8 \%$ reduction. ${ }^{11}$ The recent federal budget agreement, passed this February under the looming threat of a government shutdown, outlined at least a $\$ 2$ billion increase in $\mathrm{NIH}$ funding over the next 2 years, though the funds have yet to be appropriated.

In addition, our results suggest that pediatric researchers also are aware of the policy implications of reducing healthaccess for children, particularly vulnerable children in poverty and/or with chronic illness. Respondents prioritize opposing limitations on children's access to health insurance at a time when this issues continues to be evolving. Since 2010, the childhood uninsurance rate has dropped dramatically to its lowest recorded level (4.5\%), due to increased coverage for children in low-income families, attributable in part to the outreach efforts from the Children's Health Insurance Program, and Medicaidprogram expansion from the Affordable Care Act (ACA). ${ }^{13,14}$ Of the $~ 3.6$ million children who remain uninsured, the majority reside in states that opted not to expand Medicaid under the ACA. ${ }^{15-20}$ In the year since this survey was administered, the American Health Care Act (AHCA) passed by the US House of Representatives but not approved by the Senate, proposed significant alterations to the $A C A$, including a roadmap to convert Medicaid to block grants, ${ }^{21,22}$ which could negatively impact the funding streams in some states for children's regionalized subspecialty care. ${ }^{21,22}$ The recent renewal of the bipartisan Children's Health Insurance Program (now for 10 years) demonstrated a desire for Congress to maintain health insurance for 9 million low-middle income children. However the 4-month delay in reauthorizing the program, which threatened state budgets and health care for all children, illustrates a potential disregard for the needs of children. As calls for "entitlement reform" become increasingly popular in the US Congress, the Medicaid program remains acutely at risk. Congress recently eliminated the universal mandate for health insurance, and it is considering other measures to reform the Medicaid Expansion provisions of the ACA such as elimination of employer health insurance mandates, state-based waivers, changes to essential health benefits, and other regulations designed to protect lowincome and chronically ill patients. Meanwhile, funding for other agencies that have helped support child-health research and training-including the Maternal and Child Health Bureau and the Agency for Health Research and Quality-is being allowed to diminish.

All of these policies are potential threats to children's health, and are of demonstrable concern to all pediatric researchers. Robustly, funding NIH and ensuring access for all children to highquality health insurance are considered high priorities by SPR membership. Engagement by all members of the pediatric research community is required to ensure that elected representatives understand the implications of proposals, which may adversely affect children.

\section{ADDITIONAL INFORMATION}

Competing interests: The authors declare no competing interests.

\section{REFERENCES}

1. Ackerman, K. G., Lee, B. \& Kushner, J. A. Dissatisfaction with maintenance of certification in academic pediatrics. Pediatr. Res. 79, 240-242 (2016).

2. American Academy of Pediatrics. Blueprint for Children: How the Next President Can Build a Foundation for a Health Future 2016. https://www.aap.org/en-us/ Documents/BluePrintForChildren.pdf (2016). Accessed 1 Nov 2016.

3. Society for Pediatric Research. Membership Eligibility Criteria. https://www.aps-spr. org/SPR/membership/criteria.asp (2017). Accessed 22 Nov 2017.

4. American Academy of Pediatrics. Federal Advocacy. https://www.aap.org/en-us/ advocacy-and-policy/federal-advocacy/Pages/Federal-Advocacy.aspx (2017). Accessed 22 Nov 2017.

5. Federation of American Societies for Experimental Biology. Science, Policy, Advocacy and Communications, Federal Funding Data. http://www.faseb.org/ Science-Policy--Advocacy-and-Communications/Federal-Funding-Data.aspx (2017). Accessed 22 Nov 2017.

6. Genel, M., McCaffree, M. A., Dennery, P. A., Hay, W. W. Jr, Standon, B., Szilagyi, P. G. \& Jenkins, R. R. A National Agenda for America's Children and Adolescents in 2008: recommendations from the 15th Annual Public Policy Plenary Symposium, Annual meeting of the Pediatric Academic Societies, May 3 2008. Pediatrics 122, 843-849 (2008). 
Policy priorities for child health: results from a membership... $\mathrm{S}$ Shah et al.

7. Hay, W. W. Jr, Gitterman, D. P., Williams, D. A., Dover, G. J., Sectish, T. C. \& Schleiss, M. R. Child health research funding a policy: imperatives and investments for a healthier world. Pediatrics 125, 1259-1265 (2010).

8. Federation of American Societies for Experimental Biology. Federal Funding Data, NIH Research Funding Trends. http://www.faseb.org/Science-Policy--Advocacyand-Communications/Federal-Funding-Data/NIH-Research-Funding-Trends.aspx (2017). Accessed 22 Nov 2017.

9. Shah, S., Wong, S., Bearer, C. \& Brumberg, H. Environmental health reform in a synthetic world. Pediatr. Res. 82, 373-375 (2017).

10. Department of Health and Human Services 2018. Justification of Estimates for Appropriations Committees 2017. https://officeofbudget.od.nih.gov/pdfs/FY18/NIH \%20Overview\%20Volume\%20Final.pdf (2017). Accessed 23 May 2017.

11. National Institutes of Health Office of Budget. National Institutes of Health Historical Budget Request. https://officeofbudget.od.nih.gov/history_budget_req. html (2017). Accessed 20 May 2017.

12. Penn, A. A. Perspectives of recent trainees on career choices in neonatology. J. Perinatol. 26, S53-S56 (2006).

13. Alker, J., \& Pham, O. Nation's Uninsured Rate for Children Drops to Another Historic Low in 2016. https://ccf.georgetown.edu/wp-content/uploads/2017/09/ Uninsured-rate-for-kids-10-17.pdf (Georgetown University Health Policy Institute, 2016). Accessed 27 Dec 2017.

14. Alker, J. \& Chester, A. Children's Health Coverage Rate Now at Historic High of 95 Percent. https://ccf.georgetown.edu/wp-content/uploads/2016/11/Kids-
ACS-update-11-02-1.pdf (Georgetown University Health Policy Institute, 2016). Accessed 27 Dec 2017.

15. Shah, S. I. \& Brumberg, H. L. Predictions of the Affordable Care Act's impact on neonatal practice. J. Perinatol. 36, 586-592 (2016).

16. Medicaid and CHIP Total Enrollment in October 2017. Medicaid.gov. https://www. medicaid.gov/medicaid/program-information/medicaid-and-chip-enrollmentdata/report-highlights/child-and-chip-enrollment/index.html (2017). Accessed 3 Jan 2018.

17. Currie, J. \& Gruber, J. Health insurance eligibility, utilization of medical care, and child health. Q. J. Econ. 111, 431-466 (1996).

18. Dubay, L. \& Kenney, G. The impact of CHIP on children's insurance coverage: an analysis using the National Survey of America's Families. Health Serv. Res. 44, 2040-2059 (2009).

19. Selden, T. M. \& Hudson, J. L. Access to care and utilization among children: estimating the effects of public and private coverage. Med. Care 44, 19-26 (2006).

20. Howell, E. M. \& Kenney, G. M. The impact of the medicaid/CHIP expansions on children: a synthesis of the evidence. Med. Care Res. Rev. 69, 372-396 (2012).

21. Tollen, L. Health policy brief, medicaid primary care parity. Health Affairs 2015. https://www.healthaffairs.org/do/10.1377/hpb20150511.588737/full/ healthpolicybrief_137.pdf (2015). Accessed 3 Jan 2018.

22. Black, D. HR 1628: American Health Care Act of 2017. 115th Congress. https:// www.congress.gov/bill/115th-congress/house-bill/1628 (2017). Accessed 3 Jan 2018. 